\section{The pursuit of excellence}

Paul Hébert's call for the pursuit of excellence in health care, health education and health research in the interests of innovations for better health outcomes $^{1}$ is timely and welcome. Innovation in health will only come about by an explicit determination to integrate the scientific foundations of innovation; discovery, clinical, services, health behavior and promotion, and implementation. Hébert correctly identifies systems challenges as particular barriers to the pursuit of these laudable goals. Moreover, the evidence base for the necessary integrative approaches is penurious. ${ }^{2}$ This begs the following observation: While health professional pursuits in care, education, and research are necessary, they are not sufficient. Required is a focus on systems strengthening through an engagement with policy professionals within Canada's health and social services jurisdictions.

\section{R.J. Riopelle MD}

Chair, Department of Neurology and

Neurosurgery McGill University, Montréal, Que.

\section{REFERENCES}

1. Hébert PC. Why the pursuit of excellence matters [editorial]. CMAJ 2010;182:121.

2. Mitton C, Adair CE, Mckenzie E., et al. Knowledge transfer and exchange: review and synthesis of the literature; The Milbank Quarterly 2007; 85: 729-68.

For the full letter, go to: www.cmaj.ca/cgi/eletters /182/2/121\#275616

DOI:10.1503/cmaj.110-2036

\section{Tough choices?}

In "Tough choices: private sale of drugs in public hospitals," the authors base their argumentation on a sleightof-pen by using the concept of "medical necessity" or lack thereof. The absurdity of the medical necessity argument is readily apparent from the discrepancy in the access to cancer drugs across Canadian provinces. Could anyone argue rationally that alemtuzumab is "medically necessary" in British
Columbia or Manitoba but not in Ontario or Quebec? Can the state deny a patient a beneficial service, if the residual cost-utility falls below the customary threshold because a patient bears its major cost? The answer to this conundrum lies not in the blunt instrument of new legislation spawned by ideology, but in carefully individualized decision processes that involve all the major stakeholders.

\section{Ralph F. Bloch MD PhD MSc}

Professor, clinical epidemiology and biostatistics, Faculty of Health Sciences, McMaster University, Hamilton, Ont.

\section{REFERENCE}

1. Flood CM, Hardcastle L. Tough choices: private sale of drugs in public hospitals. CMAJ 2010;182:374-6.

For the full letter, go to: www.cmaj.ca/cgi/eletters /182/4/374\#298095

DOI:10.1503/cmaj.110-2044

\section{Indigenous health}

In the Feb. 23, 2010, issue of CMAJ, the health of indigenous people regarding food insecurity,' epidemiology of diabetes ${ }^{2}$ and birth outcomes ${ }^{3}$ was summarized. Traditional indigenous foods were not studied in the food security study. These foods, which include fish, would provide some vitamin D and significant levels of omega 3 fatty acids. However, environmental contaminants in these foods are rising and mercury is certainly a concern. There is emerging evidence that inadequate maternal vitamin D levels may increase the risk of developing diabetes in the offspring, pre-eclampsia in pregnancy, primary cesarean section rates and increased bacterial vaginosis in the first trimester. Low omega 3 fatty acid intake may contribute to the development of preeclampsia, preterm births and other adverse pregnancy outcomes.

In 2007, the Canadian Pediatric Society recommended increased vitamin D levels, especially in the Inuit and First Nations who live at higher latitudes. Improving vitamin D status is a very inexpensive intervention costing pennies a day. Omega 3 fatty acid intake recommendations in pregnancy have been around since 1999. Providing purified omega 3 supplements, although more expensive, would avoid the mercury and other toxicants found in contaminated traditional foods. Studies applying these recommendations and following outcomes may show considerable improvement in the health of the indigenous population and the rest of the nation as a whole.

Gerry K. Schwalfenberg MD

Assistant clinical professor, University of Alberta, Edmonton, Alta.

\section{REFERENCES}

1. Egeland GM, Pacey A, Cao Z, et al. Food insecurity among Inuit preschoolers: Nunavut Inuit Child Health Survey, 2007-2008. CMAJ 2010;182:243-8.

2. Dyck R, Osgood N, Lin TH, et al. Epidemiology of diabetes mellitus among First-Nations and nonFirst Nations adults. CMAJ 2010;182:249-56.

3. Luo Z.-C, Senécal S, Simonet F, et al. Birth outcomes in the Inuit-inhabited areas of Canada. CMAJ 2010;182:235-42.

For the full letter, go to: www.cmaj.ca/cgi/eletters /182/3/243\#297970

DOI:10.1503/cmaj.110-2042

\section{Children with brain injuries}

We read with interest the study "CATCH: a clinical decision rule for the use of computed tomography in children with minor head injury." The authors are to be congratulated for their efforts to clarify the role and potential benefits of computed tomography in children with minor head injuries. In addition to imaging studies, clinicians and researchers have used EEG to evaluate changes in the electrical activity of the brain following mild traumatic brain injury. In a retrospective analysis from January 2006 to December 2007 to assess the role of standard EEG recordings in children with mild traumatic brain injury, we concluded that the routine performance of an EEG is not indicated because in most of the cases it is unrevealing, and may lead to unnecessary diagnostic procedures. Notwith- 
standing the fact that the study by Osmond and colleagues needs to be confirmed in a prospective study, their results may prove an important basis for deriving a decision rule for the management in the emergency department of children with mild traumatic brain injury.

\section{Sascha Meyer MD and colleagues}

University Hospital of Saarland,

Department of Pediatric Intensive Care

Medicine, Neonatology and

Neuropediatrics, Homburg, Germany

\section{REFERENCE}

1. Osmond MH, Klassen TP, Wells GA, et al. CATCH: a clinical decision rule for the use of computed tomography in children with minor head injury. CMAJ 2010;182:341-48.

For the full letter, go to: www.cmaj.ca/cgi/eletters/ 182/4/341\#298332

DOI:10.1503/cmaj.110-2045

\section{Seasonality and H1N1}

The paper "Estimated epidemiologic parameters and morbidity associated with pandemic (H1N1) influenza" fails to consider the impact of environment - the third apex of the epidemiological triangle - on the reproductive number of H1N1. Influenza is wellknown to be a seasonal disease. The period studied by this paper fell mostly outside of what is usually considered to be "flu season." This observation calls into question the authors' core conclusion about the potential effectiveness of non-medical mitigation strategies on an in-season outbreak.

\section{Richard Schabas MD MHSc}

Medical Officer of Health, Hastings and Prince Edward Counties Health Unit, Belleville, Ont.

\section{REFERENCE}

1. Tuite AR, Greer AL, Whelan M, et al. Estimated epidemiologic parameters and morbidity associated with pandemic H1N1 influenza. CMAJ 2010;182: 131-6.

For the full letter, go to: www.cmaj.ca/cgi/eletters /182/2/131\#282043

DOI:10.1503/cmaj.110-2039

\section{Commercial ultrasound}

Re: "Proliferation of prenatal ultrasonography." I was recently made aware of what appears to be a proliferation of the availability of commercial fetal ultrasound. A young couple wanted to show me a 60-minute video ultrasound of their 34-week fetus obtained over a two-hour session during which time the uterus was poked and proded to get the baby to wake, move, suck her thumb, etc. The couple told me they were aware of friends that were also getting fetal video ultrasounds in other locations. The authors of this paper express concerns about excessive prenatal ultrasound exposure. Are they aware of what appears to be a new trend mentioned above?

\section{Edward J. Cormode MD \\ Pediatrician, retired}

\section{REFERENCES}

1. You JJ, Alter DA, Stukel TA, et al. Proliferation of prenatal ultrasonography. CMAJ 2010; 182: 143-51.

For the full letter, go to: www.cmaj.ca/cgi/eletters /182/2/143\#278694

DOI:10.1503/cmaj.110-2037

\section{Intubation in acute asthma}

Dr. Hodder and coauthors have written a detailed review describing the management of the severe asthmatic with respiratory failure requiring mechanical ventilator support.' I have a concern about their suggested approach to endotracheal intubation. Although they appropriately recommend that this procedure should be carried out by a skilled expert, they suggest rapid-sequence intubation if such help is not available. Rapid-sequence intubation in unskilled hands can have catastrophic consequences. ${ }^{2}$ I would strongly advocate a near-awake intubation with maintenance of spontaneous respiratory efforts, as an initial intervention. This can be effectively achieved in most patients, with rapid-sequence intubation used as a backup approach. Once an artificial airway has been established, sedation can be given to facilitate ventilation. It is important to bear in mind that the combination of pre-existing volume depletion, air trapping and sedative administration can cause marked hypotension and even cardiac arrest.

Stephen E. Lapinsky MB BCh MSc Mount Sinai Hospital, Toronto, Ont.

\section{REFERENCES}

1. Hodder R, Lougheed MD, Fitzgerald JM, et al. Management of acute asthma in adults in the emergency department: assisted ventilation. CMAJ 2010;182:265-72.

2. Mace SE. Challenges and advances in intubation: rapid sequence intubation. Emerg Med Clin North Am 2008;26:1043-68.

For the full letter, go to: www.cmaj.ca/cgi/eletters /182/3/265\#297996

DOI:10.1503/cmaj.110-2043

\section{The problem with sleep?}

Re: "To mandatory nap or not to mandatory nap."' Surgery residents' joke: What's the problem with every-othernight call? Answer: You miss half the good stuff.

James M. Walker MD

Geisinger Health System, Danville, USA

\section{REFERENCE}

1. Doyle S. To mandatory nap or not to mandatory nap. CMAJ 2010;182:E151-2

For the full letter, go to: www.cmaj.ca/cgi/eletters /182/3/E151\#285236

DOI:10.1503/cmaj.110-2047

\section{Letters to the editor}

In submitting a letter, you automatically consent to have it appear online and/or in print. All letters accepted for print will be edited by $C M A J$ for space and style. Most references and multiple authors' names and full affiliations will appear online only. (The full version of any letter accepted for print will be posted at cmaj.ca.) 